\title{
Experimental study on bending mechanical properties of moso bamboo
}

\author{
Yousheng Deng ${ }^{1 *}$, Chengpu Peng ${ }^{1}$ \\ ${ }^{1}$ Research Center of Plie-supported Structures, Xi'an University of Science and Technology, Xi'an China
}

\begin{abstract}
Moso bamboo, as an environmentally friendly material, has become a research hotspot in civil engineering circles, and its good mechanical properties make it have great potential in civil engineering applications. To take full advantage of moso bamboo, a series of bending tests were carried out on bamboo pipes (RBP), hollow bamboo pipes (HBP, without bamboo membrane) and bamboo pipes with concrete(BPC), and analyzed such as bending strength, flexural bearing capacity, deformation law, failure characteristics and other test results. The results showed that the smaller the diameter of moso bamboo is, the greater the bending strength and elastic modulus are; the maximum strain of BPC is 2.5 times the HBP, the distribution of strain along cross section is linear; RBP, HBP, and BPC show different failure pattern; there is a little difference between RBP and HBP that come from the same moso bamboo and have a similar diameter in limit capacity, bending strength, and elastic modulus; the flexural bearing capacity of BPC is 2.4 times the HBP, the bending strength is 1.7 times, the composite structure is effectively enhanced by concrete. The test results can provide references for the application of bamboo in landslide treatment, the supporting structure of the foundation, and other engineering.
\end{abstract}

\section{Introduction}

Bamboo is of an extremely important position in the global forest resources, known as the second forest. China is the richest country in bamboo resources with the largest distribution area of bamboo forest in the world. Bamboo is a renewable and degradable material ${ }^{[1]}$, has low cost and a short growth cycle, which can be useful within 3-5 years. Moso bamboo is also a good structure material in civil engineering with low density, great rigidity, and strength $^{[2,3]}$, used in civil engineering for thousands of years. The application research of bamboo in civil engineering has attracted extensive attention of scholars. Some scholars have examined the mechanical properties of bamboo. Because of lacking relevant theoretical systems such as material mechanics test standards, structural design methods, modern construction technical specifications, which are similar to the standards used in steel structure, concrete structure, wood structure, and other materials, moso bamboo is still not fully utilized in modern structure[4]. Nogata Fumin and Tan et al.[5-6] regarded bamboo as a composite material composed of vascular bundle and matrix, and proposed that the mechanical properties of bamboo bundle depend on the density of vascular bundle. The vascular bundle distribution in the longitudinal and radial direction is different, which leads to different mechanical properties of materials in two directions. Chung et al.[7] developed a range of experiments about the mechanical properties and buckling failure of moso bamboo and bambusa pervariabilis mcclure, stated two types of standard values of basic mechanical properties and calculation method of bearing capacity of the compressive bamboo structure. Tommy et al.[8] tested the influence of age, diameter, and other factors on the compressive strength of bamboo, obtained the general range of compressive strength, the results showed that compressive strength is reduced evidently with the increase of outer diameter. Jian et al.[9] analyzed the mechanical properties of the bamboo reinforced concrete beam, the results proved that bamboo possesses good bending strength and can be used as reinforcement for low-cost building concrete structure. Wei et al.[10] carried out a bending test of large-scale rectangular glued bamboo beam, pointed out four typical failure characteristics of glued bamboo beams, the section stiffness is the key to bearing capacity. Zhang et al.[11] tested various mechanical properties of moso bamboo pipe compared with bamboo pieces, it was pointed that there is a little difference in compressive and shear strength between the two specimens, there is a great difference in bending strength, but their variation regularity of mechanical properties is similar. Si et al[12]. analyzed the physical and mechanical properties of different sorts of bamboo, the results showed that there is a linear relationship between the dry density and compressive strength and bending strength parallel to the grain of bamboo species, pointed out a regression equation that can be used to estimate the relationship between the two species. Cheng[13] utilized the moso bamboo in the support of a shallow foundation, the supporting system composed of moso bamboo pipe pile shows better ability

\footnotetext{
*Corresponding author: dengys2009@126.com
} 
in constraining soil displacement and stability. The aforementioned studies examined the bamboo has great potential as an eco-friendly material. But its mechanical properties are related to the position and moisture content of moso bamboo and whether it contains bamboo joint. To make full use of moso bamboo, it is necessary to test its physical and mechanical properties. In the paper, a series of bending tests were carried out to analyze the bending strength, deformation law, and failure pattern of RBP and BPC.

\section{Experimental materials}

The row materials were 4 years old, selected from a bamboo forest in Xianning, Hubei. There were representatives and no defects. The specimens were placed in the room until the moisture content was $12 \sim 15 \%$. One meter long bamboo pipe was cut from the top, middle, and lower parts of the whole moso bamboo as specimens for bending test, numbered T1-1 T4-1, M1-1 M4-1, D11 4-1. The size of the specimens was $1000 \mathrm{~mm}$ long, $\mathrm{d}$ $\mathrm{mm}$ in diameter, $\mathrm{d}$ was $80 \sim 120 \mathrm{~mm}$, as shown in Fig. 1 .

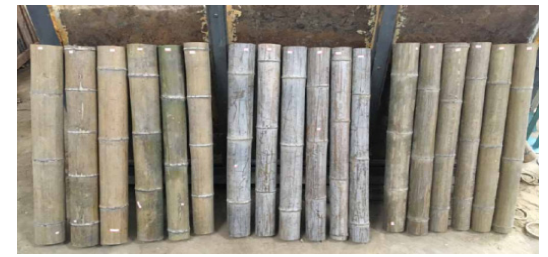

Figure 1. Specimens for bending test

\section{Bending test for moso bamboo}

\subsection{Bending strength and elastic modulus}

\section{(1) Experiment scheme}

Both ends of the specimen were simply supported, tested through the third-point bending method, shown in Fig. 2. Five strain gauges were attached on the cross section at the middle span to measure the strain variation. Three displacement meters were placed in the middle span and points of trisection to measure the deflection of the specimen, the data was collected by a static strain test system. According to the Determination of physical and mechanical properties of bamboo culm (LY/T2564-2015), the preload was not more than $100 \mathrm{~N}$, applied with uniform speed. The specimens were damaged in 1 2 min. The limit load and deflection at the middle span were recorded.

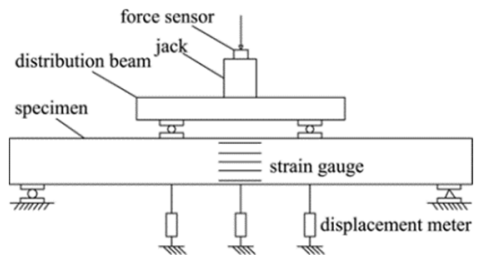

(a) Schematic diagram of bending test

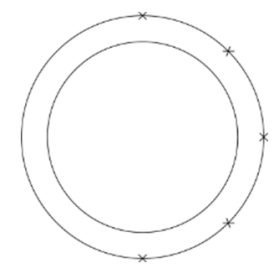

(b) The distribution of strain gauge

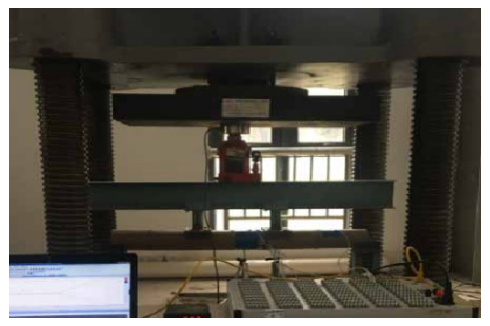

(c) Loading diagram

Figure 2. Equipment for bending test of moso bamboo

(2) Results and analysis

From the tested data, the bending $\operatorname{strength}(\sigma)$ and elastic modulus $(E)$ can be calculated by Eq. 1 and 2 .

$$
\begin{gathered}
\sigma=\frac{F_{\max } \times L \times D_{\text {min }}}{12 I} \\
E=\frac{23 \times \Delta F \times L^{3}}{1296 \times \Delta \delta \times I}
\end{gathered}
$$

Where $F_{\text {max }}$ is limit load, $L$ is the length of the specimen, $D_{\min }$ is the minimum diameter at the loading points, $I$ is the second moment of area of the beam crosssection about the neutral axis, $\Delta F$ is the difference between the upper and lower limit loads, $\Delta \delta$ is the deflection change at the middle span between the upper and lower limit load.

At the initial stage of loading, the specimens were in the elastic stage, the development trend of loaddisplacement curves is basically the same, showing a linear relationship, indicated in Fig. 3. With the continuous increase of load, the plastic deformation of the specimens occurred, the bending specimens located from different parts showed different bearing characteristics. The cracks firstly appeared at the support points of the specimen without bamboo joint, accompanied by a small tearing sound. When the load was up to the limit, it made a huge noise and cracks were obvious. The cracking load of the bending specimen was about $90 \%$ of the ultimate, the failure mode is brittle. The typical failure mode of specimens is shown in Fig. 4.

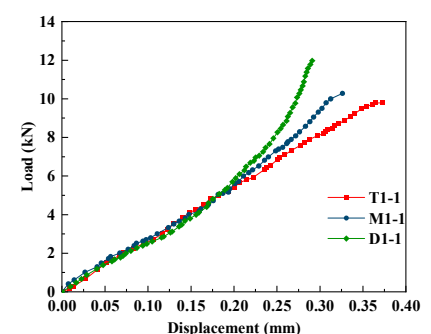

Figure 3. Load-displacement curves at the middle span 
The typical failure characteristics of bamboo bending specimens were as follows: there were two symmetrical cracks with the same length in the tensile zone of the section with smaller diameter or the support section without bamboo joint, the angle between the two cracks was $120^{\circ}$, a crack appeared at the bottom the tensile zone of some specimens, the bamboo was damaged by tension. Most of the cracks in the tensile zone were symmetrically distributed, the crack length was approximately the same. It was indicated that the failure of the end section is an important factor influencing the whole bearing capacity of bamboo pipe, and there is an unstable phenomenon at the bamboo joint.

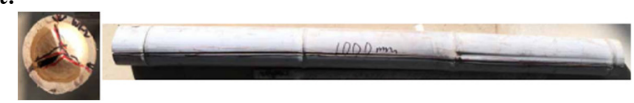

(a)T1-1

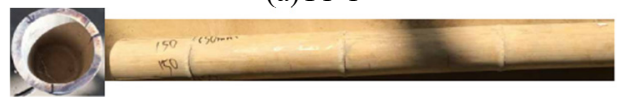

(c)D1-1

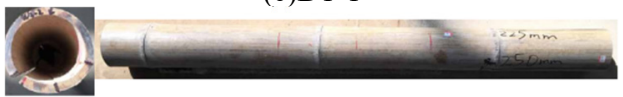

(e)M2-1
The parameters of specimens and test results are shown in Table 1. The results indicated that the smaller the diameter is, the greater the flexural strength and elastic modulus are. The flexural bearing capacity was up to 12.1 $\mathrm{kN}$.

\subsection{Flexural bearing capacity and bending strain}

The test load was applied step by step, the preload was 1 $\mathrm{kN}$. At each loading step, the load was $3 \mathrm{kN}$, the period was $10 \mathrm{~min}$.
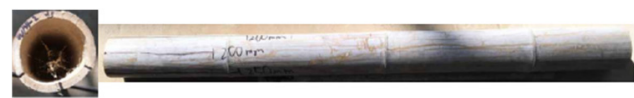

(b)M1-1

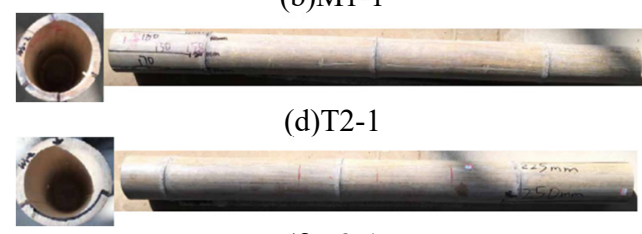

(f)D2-1

Figure 4. Typical failure pattern

Table1. Parameters and experiment results

\begin{tabular}{ccccccccc}
\hline Number & $D_{\min } / \mathrm{mm}$ & $L / \mathrm{mm}$ & $F_{\max } / \mathrm{kN}$ & $I / \mathrm{mm} 4$ & $\sigma / \mathrm{MPa}$ & $\Delta F / \mathrm{kN}$ & $\Delta \delta / \mathrm{mm}$ & $E / \mathrm{GPa}$ \\
\hline T1-1 & 75.55 & 900 & 9.8 & 971727 & 57.14 & 1.9 & 0.066 & 381 \\
M1-1 & 84.57 & 900 & 10.3 & 1381082 & 47.30 & 2.1 & .094 & 209 \\
D1-1 & 88.37 & 900 & 12.1 & 1712128 & 46.84 & 2.2 & 0.101 & 165 \\
T2-1 & 78.46 & 900 & 6.9 & 982808 & 41.31 & 1.4 & 0.073 & 251 \\
T2-1 & 81.42 & 900 & 9.5 & 1238366 & 46.85 & 1.5 & 0.084 & 187 \\
D2-1 & 88.37 & 900 & 12.1 & 1712128 & 46.84 & 2.2 & 0.101 & 165 \\
\hline
\end{tabular}

Table2. Test results

\begin{tabular}{cccccc}
\hline Number & $F_{\max } / \mathrm{kN}$ & $D / \mathrm{mm}$ & $\varepsilon_{c} / 10^{-6}$ & $\varepsilon_{t} / 10^{-6}$ & $f_{t} / \mathrm{mm}$ \\
\hline T3-1 & 7.3 & 78.60 & 1677 & 3002 & 0.302 \\
M3-1 & 6.1 & 90.14 & 1515 & 1911 & 0.192 \\
D3-1 & 6.9 & 98.73 & 1703 & 2166 & 0.206 \\
T4-1 & 5.0 & 86.14 & 1184 & 1522 & 0.180 \\
M4-1 & 7.2 & 90.58 & 2159 & 2378 & 0.281 \\
D4-1 & 8.9 & 104.61 & 1369 & 1994 & 0.179 \\
\hline
\end{tabular}

Where $F_{\text {max }}$ is the limit load, $D$ is the diameter of specimens, $\varepsilon_{c}, \varepsilon_{t}$ is the compressive and tensile strain corresponding to the ultimate load, $f_{t}$ is the deflection at the middle point corresponding to the limit load.

As shown in Table 2, the diameter of specimens is $70 \sim 110 \mathrm{~mm}$, the maximum compressive strain is $1100 \sim 2200 \mu \varepsilon$, the maximum tensile strain is
$1500 \sim 3100 \mu \varepsilon$, the maximum tensile strain of the specimens is generally greater than the maximum compressive strain. The load-strain curves of each test point at the section of the middle span are shown in Fig. 5, the negative value is compressive strain, the positive is tensile strain. At the whole loading stage, the load-strain relationship is basically linear in both tension and compression areas.
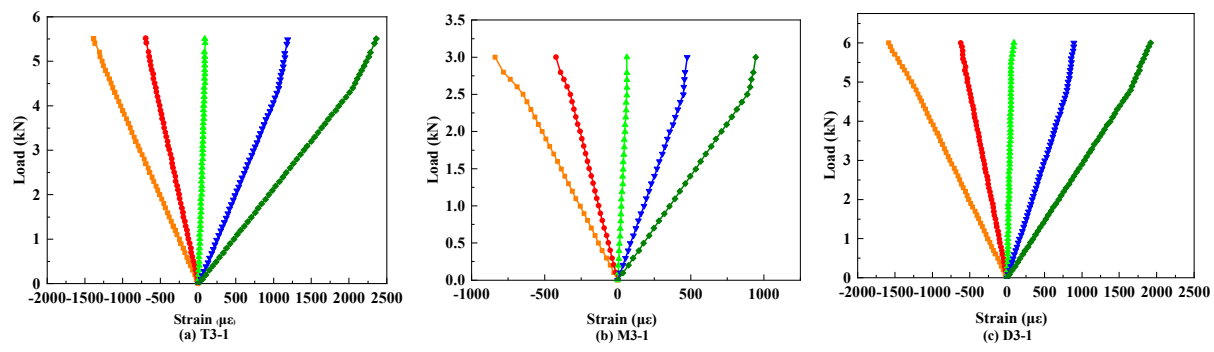

Figure 5. Load-strain curves of the section at middle span 
The strain variation along the height of the cross section at the middle span is shown in Fig. 6. It is evident that the development trend of the curves is linear. The phenomenon conforms to the plane section assumption.
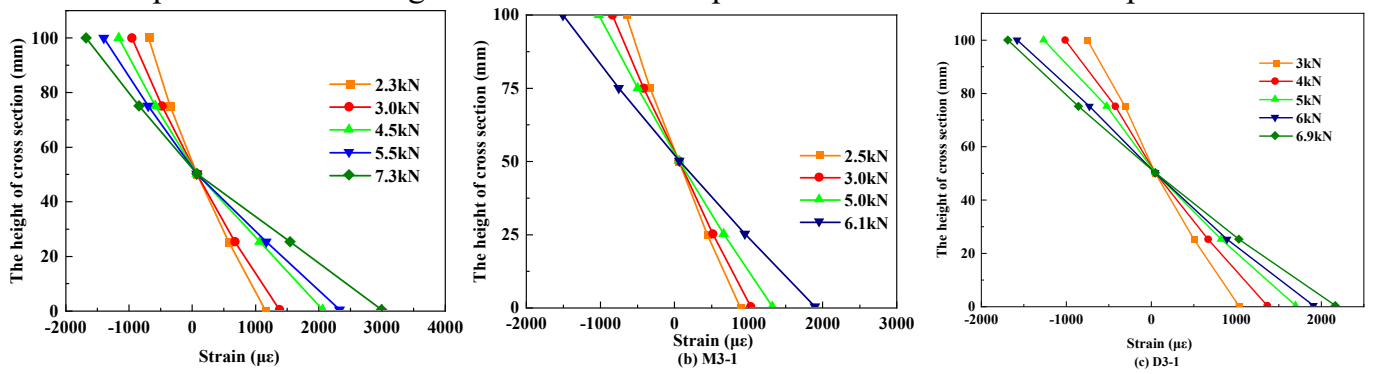

Figure 6. The height-strain curves

\section{BPC bending test}

\subsection{Bending strength and elastic modulus}

\section{(1) test scheme}

Specimens were six, divided into two groups according to $\mathrm{RBP}(\mathrm{Y}), \mathrm{HBP}(\mathrm{K}), \mathrm{BPC}(\mathrm{KH})$. The first group was HBP, numbered $\mathrm{K}-1, \mathrm{~K}-2, \mathrm{~K}-3$. The second group was numbered Y-1, Y-2, KH-1. According to the Determination of physical and mechanical properties of bamboo culm (LY/T2564-2015), the preload, not more than $100 \mathrm{~N}$, was applied with uniform speed, the specimens were damaged in 1 2 min. The limit load and deflection of the middle span were recorded.

(2) Results and analysis

There were different failure modes between RBP, HBP, and BPC. There is a linear relationship between load and displacement at the middle span. When the bamboo pipe was destroyed, there were three cracks at the tensile zone, the one at the bottom, the angle between the other two cracks was $120^{\circ}$. The failure characteristics of RBP and HBP were the same. A few specimens with large diameters were damaged by compression, there were evident cracks at the compressive area. First, the concrete at the tensile area was destroyed. Second, the cracks appeared evidently at the bottom of bamboo pipe. Finally, the bamboo at the compressive area was damaged. There were apparent cracks. The load-displacement curves at the middle span are shown in Fig. 7.

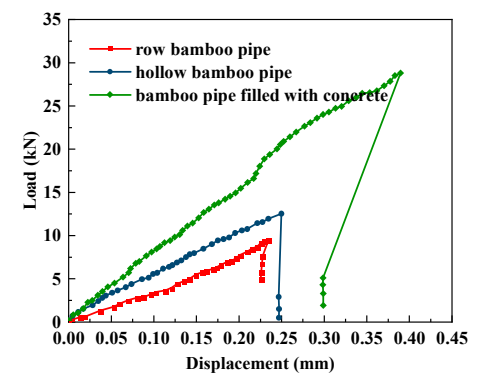

Figure 7. Load-displacement curves at the middle span

The results indicated that the difference between RBP and HBP is little in limit load, bending strength, and elastic modulus, the specimens were from the same bamboo and with the same diameter. The HBP showed greater bearing properties. Therefore, the bamboo joint has little influence on the flexural bearing capacity of bamboo. The flexural bearing capacity of BPC is 2.4 times the HBP with the same diameter, and the bending strength is 1.7 times. The bearing capacity of the composite structure is increased by concrete.

Table3. Parameters and test results

\begin{tabular}{ccccccccc}
\hline Number & $D_{\min } / \mathrm{mm}$ & $L / \mathrm{mm}$ & $F_{\max } / \mathrm{kN}$ & $I / \mathrm{mm} 4$ & $\sigma / \mathrm{MPa}$ & $\Delta F / \mathrm{kN}$ & $\Delta \delta / \mathrm{mm}$ & $E / \mathrm{GPa}$ \\
\hline $\mathrm{K}-1$ & 90.58 & 900 & 7.2 & 1934133 & 25.29 & 1.4 & 0.040 & 236 \\
$\mathrm{Y}-1$ & 90.14 & 900 & 6.1 & 1804873 & 22.85 & 1.3 & 0.041 & 229 \\
$\mathrm{~K}-2$ & 92.71 & 900 & 12.4 & 2271301 & 37.96 & 2.4 & 0.063 & 218 \\
Y-2 & 93.52 & 900 & 9.3 & 2258491 & 28.88 & 1.9 & 0.050 & 216 \\
$\mathrm{~K}-3$ & 115.61 & 900 & 12 & 5800199 & 17.94 & 2.5 & 0.038 & 146 \\
$\mathrm{KH}-1$ & 112.09 & 900 & 28.7 & 7743542 & 31.16 & 6 & 0.082 & 123 \\
\hline
\end{tabular}

\subsection{Flexural bearing capacity and bending strain}

(1) Test scheme

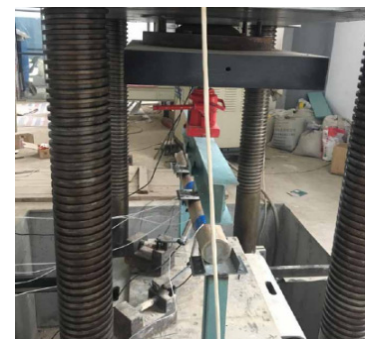

Figure 8. Loading test diagram
Specimens were six, divided into three groups. The first group was RBP, numbered Y-4, Y-5, the second group was HBP, numbered K-4, K-5, the third group was BPC, numbered KH-4, KH-5. The load was applied step by step. The preload was $1 \mathrm{kN}$, the load was $3 \mathrm{kN}$ in each loading step. The period of each step was $10 \mathrm{~min}$. the loading diagram is shown in Fig. 8.

(2) Test results and analysis

The test results are shown in Table 4. The diameter of specimens is $90 \sim 120 \mathrm{~mm}$. For HBP bending specimens, the maximum compressive strain is $1100 \sim 2200 \mu \varepsilon$, the maximum tensile strain is $2000 \sim 3400 \mu \varepsilon$. For BPC, the maximum compressive strain is $2600 \sim 3400 \mu \varepsilon$, the maximum tensile strain is $4500 \sim 6100 \mu \varepsilon$. The maximum 
tensile strain of bending specimens is generally greater than the compressive, and the maximum tensile strain of $\mathrm{BPC}$ is 1.8 times the compressive. The maximum strain of BPC specimens is 2.5 times the HPC.

The load-strain curves of each test point at the section of the middle span are shown in Fig. 9 and 10. It is indicated that the strain is linearly related to the load in both compressive and tensile areas at the whole loading stage

Table4. Test results

\begin{tabular}{cccccc}
\hline Number & $F_{\max } / \mathrm{kN}$ & $D / \mathrm{mm}$ & $\varepsilon_{c} / 10^{-6}$ & $\varepsilon_{t} / 10^{-6}$ & $f_{t} / \mathrm{mm}$ \\
\hline Y-4 & 6.1 & 90.14 & -1515 & 1911 & 0.192 \\
Y-5 & 6.9 & 98.73 & -1089 & 2166 & 0.206 \\
K-4 & 7.2 & 90.58 & -2519 & 2378 & 0.281 \\
K-5 & 8.9 & 109.88 & -1074 & 1994 & 0.179 \\
KH-4 & 21.4 & 110.40 & -2627 & 4554 & 0.294 \\
KH-5 & 27.1 & 110.80 & -3388 & 6031 & 0.267 \\
\hline
\end{tabular}
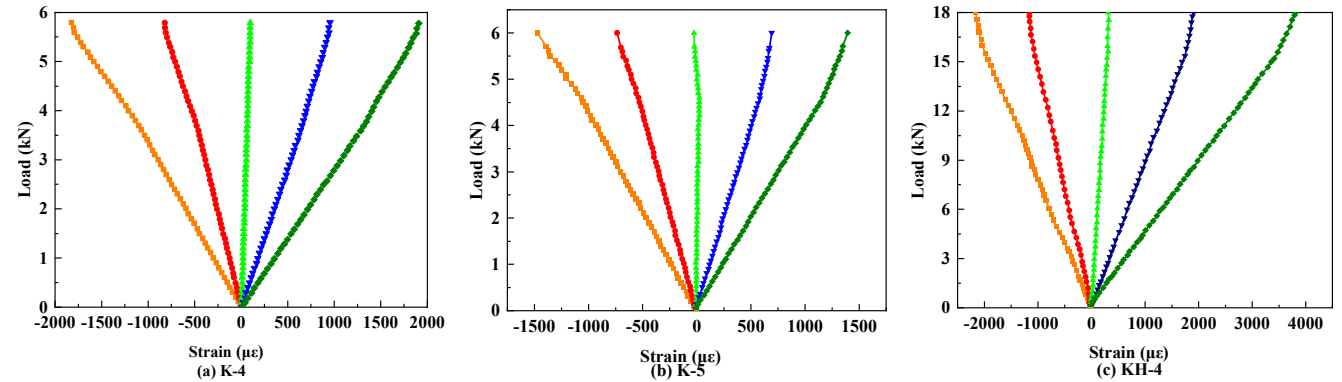

Figure 9. Load-strain curves of the bamboo section at middle span
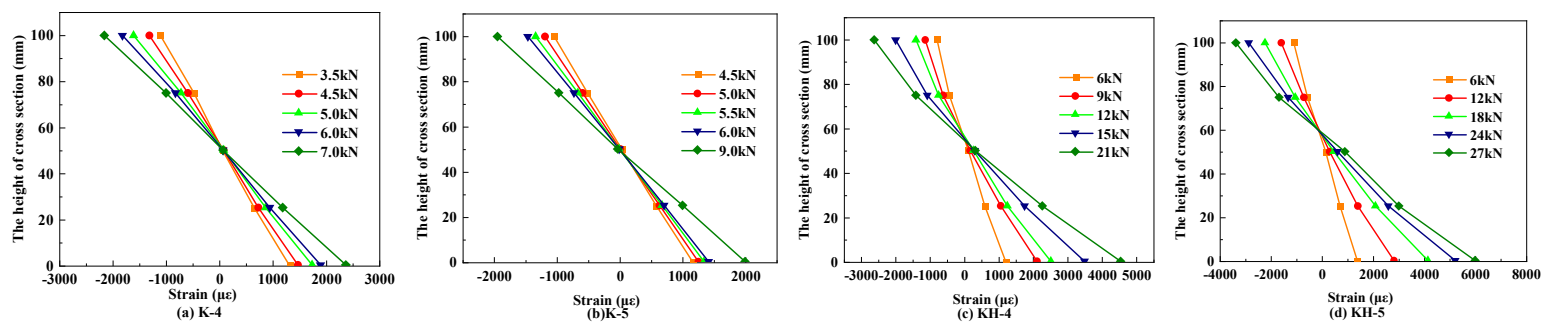

Figure 10. The height of cross section-strain curves

\section{5 conclusion}

(1) The diameter of the bamboo pipe was 70 100 $\mathrm{mm}$, the smaller the diameter was, the greater the bending strength and elastic modulus were. The flexural bearing capacity of RBP was up to 12.1 $\mathrm{kN}$.

(2) The maximum strain of the BPC bending specimen was 2.5 times the the HBP specimen. The load-strain relationship of HBP and BPC at each test point was basically linear, whether in the tensile or compressive zone. The relationship conformed to the plane section assumption.

(3) The bending failure mode of RBP, HBP, and BPC was different. The difference of RBP and HBP from the same bamboo was a little in limit load, bending strength, and elastic modulus. The flexural bearing capacity of BPC was 2.4 times the HBP with the same diameter, and the bending strength was 1.7 times.

\section{References}

1. LI Hui, LI Xiaohua, LI Xingong, et al. Development Status of Standards on Bamboo Structure Engineering Material[J]. China Standardization, 2012, (10): 89-92.

2. ZHANG Qisheng. Industrial Utilization of Bamboo in China[M]. Beijing: China Forestry Publishing House, 1995:1-12.

3. ZHANG Qisheng. Attaching Importance to Science and Innovation in the Processing and Utilization of Bamboo Timber in China[J]. Journal of Zhejiang A\&F University, 2003, 20(1): 1-4.

4. XIAO Yan, SHAN Bo. GluBam Structures[M]. Beijing: China Architecture \& Building Press, 2013, 8.

5. Nogata Fumio. Intelligent Functionally Graded Material: Bamboo[J]. Composites Engineering, 1995,5(7):743-751.

6. Tan T. Mechanical Properties of Functionally Graded Hierarchal Bamboo Structures[OL]. Acta Biomater, 2011. 
7. K.F. Chung, W.K. Yu. Mechanical Properties of Structural Bamboo for Bamboo Scaffoldings[J]. Engineering Structures, 2002, 24: 2-10.

8. Y. Lo Tommy, H. Z Cui, et al. The Effect of Fiber Density on Strength Capacity of Bamboo[J]. Science Direct, 2004, 58(21): 2595-2598.

9. Jain SK, Kurhekar SP, Wadekar C. Strength Analysis of Bamboo and Steel Reinforced Concrete Beam[J]. Engineering\& Technology in India , 2015, 6(1): 4145.

10. WEI Yang, JIANG Shenxue, ZHANG Qisheng, et al. Experimental Study on Flexural Performance of Bamboo Beam[J]. Building Structure, 2010(1): 88-91.

11. ZHANG Dan, WANG Ge, ZHANG Wenfu, et al. Mechanical Properties of Phyllostachys Pubescens[J]. Journal of Central South University of Forestry\&Technology, 2012, 32(7): 119-123.

12. SITU Chunnan, DU Wenjun, WANG Jian, et al. The Relationship between Air Dry Density and Bamboo Compressive and Flexural Strength of the Main Bamboo Species in Chishui City, Guizhou Provience[J]. Journal of Bamboo Research, 2012, (02): 16-19.

13. CHENG Zhihe. Study on Bearing Characteristics of Dentate Row Bamboo Pile-Composite Soil Nailing System[D]. Xi'an University of Science and Technology, 2020.

14. Y/T2564-2015, Determination of physical and mechanical properties of bamboo culm[S]. Beijing: Standards Press of China, 2015. 